\title{
PReserch Square \\ Scenario-based Analysis of the Impacts of Lake Drying on Sustainable Food Production
}

Bakhtiar Feizizzadeh ( $\square$ Feizizab@hu-berlin.de )

Humboldt University of Berlin

\section{Tobia Lakes}

Humboldt University of Berlin

Davoud Omarzadeh

University of Tabriz

Ayyoob Sharifi

Hiroshima University

Thomas Blaschke

University of Salzburg

Sadra Karimzadeh

University of Tabriz

\section{Research Article}

Keywords: climate change, predominantly, sustainable food production (SFP),agricultural water consumption.

Posted Date: October 1st, 2021

DOl: https://doi.org/10.21203/rs.3.rs-934137/v1

License: (c) (i) This work is licensed under a Creative Commons Attribution 4.0 International License.

Read Full License 


\section{Abstract}

In many parts of the world, lake drying is caused by water management failures, while the phenomenon is exacerbated by climate change. Lake Urmia in Northern Iran is drying up at such an alarming rate that it is considered to be a dying lake, which has dire consequences for the whole region. While salinization caused by a dying lake is well understood and known to influence the local and regional food production, other potential impacts are as yet unknown. Food production in the Urmia region has predominantly been regionally-oriented and sustainable, particularly in terms of water demand. To explore current and projected impacts of the dying lake on sustainable food production (SFP) we investigated changes in climatic conditions, land use, and land degradation for the period 1990-2020. We examined the environmental impacts of lake drought on SFP through an integrated scenario-based geoinformation framework. The results show that the lake drought has significantly affected food production and has reduced the proportion of SFP over the past three decades. Based on a combination of cellular automata and Markov modelling, the conditions are projected for the next 30 years and are predicted to exacerbate further. To mitigate these issues and support SFP, this research provides some policy recommendations and results for tangible action plans. We consider the modification of cropping patterns towards low water demand crops as one the cheapest and most efficient solutions for reducing the overall agricultural water consumption.

\section{Introduction}

The significance of large lakes as significant freshwater resources is widely acknowledged ${ }^{1}$. Among other effects, large lakes provide recreational, economic, and ecosystem services to millions of inhabitants worldwide. Global environmental changes have had significant impacts on many lakes in recent decades. Some well-known lakes are shrinking or drying up, and some lakes are even dying - like Lake Urmia in Northern Iran. Lake drying can lead to major environmental and socioeconomic problems such as water scarcity, land degradation, and food shortages. Lakes world-wide have experienced at least 4 periods of significant shrinkage due to climatic changes in the last 5 million years. Between 7.65 million and 7.9 million years ago, lake water levels dropped by up to 250 meters $^{2}$. Many lakes around the world currently face the impacts of climate change. Some noteworthy examples include Lake Chad, Sea of Galilee, Walker Lake, Aral Sea, Lake Poopo, Lake Urmia, Great Salt Lake, Lake Tanganyika, Lake Assal, Lake Faguibine, The Dead Sea, Lake Titicaca, Lake Puzhal, Owens Lake, Poyang Lake, Lake Chapala, Lake Mead, Lake Albert, Hamun Lake, or Mono Lake.

Among other things, the shrinking and drying up of lakes may significantly impact Sustainable Food Production (SFP). Given the potential impacts of the rapid rates of global population growth and the projected environmental changes on SFP, the United Nations (UN) and local governments increasingly acknowledge the need to address food security as one of the major challenges in the coming decades 4 . According to the $\mathrm{UN}^{5}$, the world population will reach about 9.7 billion by 2050 . While this will increase the global demand for food resources, global environmental changes are expected to negatively impact 
the food production capacity, thereby diminishing the capacity for SFP. Addressing SFP in the context of lake drying is particularly important as it is widely known that the land degradation of the lake ecosystems could have ramifications for peace, quality of life, and food security. When dying lakes lead to and/or intensify salinization (e.g., Lake Urmia and Great Salt Lake), the environmental and social impacts on SFP will be more significant and obvious.

Overall, lake drying could pose significant challenges for the provision of reliable, affordable, and nutritious food sources required for maintaining the health and wellbeing of the global population.

Accordingly, the main goal of this research is to apply an integrated geoinformation approach to examine the SFP in lake drying environments. We focus on Lake Urmia as a case study. The proposed integrated geoinformation approach could support international and local decision-makers and authorities in developing efficient policies for mitigating the impacts of climatic changes on the fragile ecosystems of drying lakes. Additionally, the results of the current study and application of the proposed approach to other major dying lakes could inform the development and implementation of action plans that can, ultimately, contribute to preventing large-scale food crises and human suffering ${ }^{8}$.

\section{The Case Of Lake Urmia}

Lake Urmia is one of the most hyper-saline and well-known drying (and even dying) lakes, which has been drying up since 2000. The lake, at an elevation of 1286 meter above mean sea level and with an area of $5000 \mathrm{~km}^{2}$, is located in north-western Iran (Supplementary Fig. 1). Lake Urmia and its watershed are critical in the daily life of millions of people as well as 226 species of birds and other animals. The Lake Urmia Basin (LUB), with an area of $51,876 \mathrm{~km}^{2}$, is critical as it hosts agricultural activities for SFP and industrial activities. Extensive plains and fertile agricultural farmlands surrounding the lakes have made LUB one of the most critical areas for food production and animal husbandry. According to the Iranian Ministry of Agriculture ${ }^{9}$ (IMA, 2021), with about 500,000 hectares of farmlands (360,000 croplands and 140,000 orchards), the LUB accounts for $8.47 \%$ of the total area of farmland in Iran (5,900,895 hectares). There are 42 cities and 520 villages in the LUB, according to the National Statistics Center of $\operatorname{Iran}^{10}$. Based on the latest Iranian census (2016), 7.3 million people live in the LUB, which is about $9.2 \%$ of the total population of Iran. Due to climate change and intensive land use/cover changes (LUCC), the lake has lost about 65-85 percent of its surface area since 2000, and this has increased the expanse of flat salty areas. Inappropriate irrigation practices are another factor contributing to this drying up process. As a result of climate change and extensive anthropogenic pressure, the ecosystem of the LUB has changed drastically. Based on the critical environmental situation observed as a result of the gradual drying up of the lake, it is also anticipated that salt and dust storms, as well as extensive soil and water salinization will be the major environmental issues that will threaten public health as well as the SFP in the coming decades. From the environmental perspective, it is believed that a reduction in the lake's water level will lead to the formation of salt domes and intensify desertification, thereby threatening the productivity of the nearby farmland by means of soil and water salinization. As with other drying lakes, there is also great concern that the lake will completely dry up in the future (See Supplementary Fig. 2 as an example). 


\section{Climate Change Impacts}

The impact of climate change on SFP is one of the most threatening environmental challenges for today's societies. The LUB, with a semi-arid climate, an average annual precipitation (AAP) of 350 millimeters $(\mathrm{mm})$ and an average annual temperature (AAT) of 12.5 centigrade (C), has been experiencing an intense drought over the past decades ${ }^{11-16}$. Figure 1 a represents the AAP and AAT trends for the past 30 years in the LUB. As this figure shows, there were several stages of drought, especially from 1995 (465 $\mathrm{mm})$ to $1998(268 \mathrm{~mm})$. There was a slight increase in the AAP between $2000(210 \mathrm{~mm})$ and 2002 (390 $\mathrm{mm}$ ). While the general drought continued until 2017 when the LUB received less than $155.47 \mathrm{~mm}$ AAP, the AAP has increased between $2018(309.75 \mathrm{~mm})$ and $2020(507.1 \mathrm{~mm})$, which has led to an increase in the lake's surface area for two consecutive years. The figures also show a considerable AAP decrease in 2021. The AAT trends show a slight increase of about 2 degrees between 1995 (11.7 C) and 2018 (13.75 C). The spatial distribution of temperature at the basin level shows that the drought of the lake has a direct spatial correlation with the temperature distribution, whereby the temperature around the lake increases as the lake continues to shrink. Figures $1 \mathrm{~b}$ and $c$ represent the impacts of climate change on the water body of Lake Urmia between 1990 and 2020. As this figure shows, the size of the lake reduced significantly between 2005 and 2015, when it lost about $80 \%$ of its area. Between 2018 and 2020, a slight increase in surface area can be observed due to the increasing AAP from 2018 to 2020.

\section{Anthropogenic Pressure}

The rapid industrial development and increasing resource demands in the past two centuries have led to major land use/cover changes (LUCC), land degradation, and deforestation in many parts of the world. Understanding the spatiotemporal pattern of LUCC provides critical information for more efficient management practices towards sustainable development and SFP ${ }^{17}$. In addition, it is acknowledged that intensive LUCC negatively impact the environment and the socioeconomic conditions ${ }^{18}$. In most drying lake ecosystems, the insufficient and irrational LUCC cause a variety of environmental pressures and issues that further complicate global crises such as food insecurity ${ }^{19}$. In the context of LUB, the results of this study indicate that extensive LUCC have occurred in the past three decades. Figure 2 represents the LUCC maps for LUB derived from satellite images using image processing methods. According to our results, the area of croplands and cultivated area significantly increased from 2005 to 2015, which contributed to the Lake Urmia drought through the increase in the water demand and extracting water from the nearby aquifers for farmland irrigation. It is worth mentioning that the agriculture system in Iran is essentially based on the traditional irrigation systems of flood/surface irrigation, which require large amounts of water. In addition, farmers around the lake mainly produce high-water demand plants and crops such as onions, tomatoes, potatoes, sugar beets, grapes, apples, peaches, and nectarines, which has also contributed to the lake drought. The changes between 1990 and 2020 represent an intensive growth of the settlement areas, dry and fallow lands, and orchards. At the same time, the rangeland areas and rocky outcrops decreased. Based on these maps, the LUCC were computed to affect about 2,000,000 
hectares, which is equivalent to $47.15 \%$ of the LUB. The main change was observed to be in the rangelands $(-70.12 \%)$. In the second and third rank, the orchards with $+41.25 \%$ and the croplands with + $36.61 \%$ have also experienced considerable changes in area. The surface area of Lake Urmia has also experienced significant changes (Fig. 1 bc). However, the water body of the lake increased in 2020. This increase is the result of increased awareness about the critical conditions of the lake, and the implementation of several policies to limit the expansion of farmlands and prohibit the cultivation of high-water demand crops in the LUB, together with an increase in AAP between 2018 and 2020.

\section{Land Degradation}

Land degradation is one of the unavoidable consequences of lake drying, especially in the LUB ${ }^{3}$. In this study, the soil salinization and land subsidence were monitored to detect the impacts of the Lake Urmia drought on the land degradation of the surrounding areas. Therefore, the soil salinization from 1990 to 2020 was evaluated using earth observation satellite images. The resulting soil salinity maps based on the Combined Spectral Response Index (CSRI) are presented in Fig. 3. As this figure shows, the salty lands/deserts and soil salinity in the LUB have significantly increased in the eastern area surrounding the lake. Figure 3 shows that the salty lands and salinization continuously increased from 1995 to 2015, with the most significant increase in 2015 when the lake reached its worst critical condition. Figure $3 i$ shows the trend of the water body and soil salinity for the study years and the spatial correlation between the lake drought and the extension of soil salinity. From the hydrodynamic perspective, it must be indicated that the elevation of the lake bed increases from west to east, which means that the water depth in the eastern area of the lake is much less than in the western areas. Thus, the lake generally shrinks from east to west. In addition to climate change and intensive LUCC, the causeway that divides the lake into north and south has changed the balance of water around the lake. The causeway was constructed to connect Tabriz and Urmia, two major cities that are located on the western and eastern sides of the lake, respectively. The causeway has reduced the normal water circulation by about $48-50 \%$. As a result, the salt density in the northern part and the concentration difference between the two parts have increased by about $49 \%$, which is also another environmental change that has exacerbated the lake drought and intensified the associated environmental impacts ${ }^{20}$.

Land subsidence is another aspect of land degradation that we evaluated for the 2015 to 2020 timeframe based on the available Synthetic Aperture Radar (SAR) dataset. Figure 3h shows the comparison of the 2015 and 2020 SAR images used to compute the land subsidence ratio in the LUB. Based on the results, the maximum and minimum land subsidence velocity in the study area were computed to be -2.26 $\mathrm{mm} /$ year and $-8.13 \mathrm{~mm} /$ year, respectively. The number of legal and illegal wells in the LUB was estimated to be 87,242 , and the spatial distribution of subsidence areas show a meaningful correlation with the density of the excavated wells in the western and eastern plains of Lake Urmia. This implies that water extraction for drinking and agricultural- and industrial demands play an essential role in the progressive land subsidence of the study area. Patterns of intensive land subsidence have also been reported by other studies in different parts of the LUB ${ }^{21-24}$ (See Supplementary Fig. 3 as an example). 


\section{Groundwater Resource Salinization}

Earlier research indicated that the intensive groundwater extraction resulted in a negative balance in the aquifer. Nowadays, the tangible results of this can be observed as groundwater salinization and land subsidence take hold in the LUB ${ }^{21-25}$. Based on the groundwater level simulation, the intensive groundwater extraction for agricultural and industrial activities has resulted in at least 5-15 m of groundwater drawdown, which is about a $50-60 \%$ decline over the past three decades ${ }^{26}$. According to Lake Urmia Restoration Program ${ }^{27}$, there are about 76 dams and 87, 243 wells in the LUB. Figure 4 shows the results of spatiotemporal modeling of groundwater quality monitoring from 2000-2020 (based on the data availability) derived using the samples and chemical analysis of 856 wells in the LUB. Results show that the extraction from adjacent aquifers has changed the groundwater resource balance and increased the interaction of salt water and fresh groundwater. The results of this research showed that the groundwater quality in the surrounding area, especially in the southern and western areas, has been impacted by the hyper-salinity of the lake water and the processes of saltwater encroachment and seawater intrusion. Technically, the excessive discharge of aquifers and the disruption of the groundwater resources leads to supplant the interphase threshold and progress of the saltwater to adjunct aquifers, which is also acknowledged by early studies ${ }^{28}$ (See Supplementary Fig. 4 and Fig. 5 for spatial distribution of the wells and trend of groundwater discharge).

The anthropogenic sources of contaminants, such as chemical fertilizers, industrial waste, and untreated sewage water, might also be significant factors causing the excessive degradation of the groundwater quality. The principal component analysis (PCA) identified two main factors in almost all the aquifers and three main factors in the shore of the lake, which explained more than $80 \%$ of the total variance. From a hydrodynamic perspective, it can be assumed that, based on the hyper-saline nature of Lake Urmia, the total hardness and salinity of the groundwater is related to the interaction of the salt water and freshwater aquifers and the dissolution of bedrock material, which are the dominant processes affecting the groundwater quality in the surrounding areas. The degradation can result from a combination of natural and anthropogenic processes, but these can be closely related. Based on the water quality index (WQI) values, computed to assess the quality of the groundwater of the LUB for drinking water purposes, approximately $48 \%$ of the groundwater samples were identified to have poor quality and be unsuitable for drinking and agricultural purposes, according to the World Health Organization standards. Based on this, we conclude that the combined approach of a multivariate statistical technique and spatial analysis is effective in helping us understand the factors determining the groundwater quality. According to the results, the WQI has essentially increased from 2000 to 2015 (6920.06, 11660.09 and 13456.02), indicating a reduction in the quality of water used for drinking and agricultural activities. However, from 2015-2020 there is a slight reduction (11470.8), which could be explained by the increase in the AAP and the policies for controlling the groundwater extraction as part of Lake Urmia Restoration Program. Results of the WQI analysis represent the impacts of the hyper-saline water as well as the distribution of the salt from the lake bed to the farmlands, which makes them unsuitable for SFP. 


\section{Prediction of the environmental impacts of lake drought on SFP}

After identifying the trend of changes from 1990 to 2020, we identified the current limitations and opportunities for SFP in the LUB. Soil and aquifer salinization forecasting maps can be used to optimize management practices and prevent SFP from being compromised in the future. We used the CA-Markov method (see method section) to predict the future development for the years 2030, 2040 and 2050 (Fig. 5). As Fig. 5 shows, the Lake Urmia drought will continue in the coming decades, and by 2050 only the northern part of the lake will remain while all other parts will be covered by salt and dust. As shown in Fig. $5 a, b$, and $c$, the groundwater quality will be fundamentally impacted by the lake seawater intrusion due to the extensive water extraction from the aquifer. As these figures show, the groundwater salinization will impact almost all aquifers around the lake, which will, in turn, intensify the water scarcity and affect the water supply for drinking as well as for industrial- and agricultural activities. Figure $5 \mathrm{~d}$, e, and $f$ also show the predicted soil salinization resulting from the lake drought. Based on these maps, the soil salinization will extend to the eastern and southern parts where the most productive farmlands are located and several million tons of food is being produced annually (See Supplementary table 1).

Based on the trend of climate change, land degradation, water salinity, LUCC, and environmental issues, we aimed to develop SFP scenarios in the LUB. This step was implemented using a GIS-based multiple spatial analysis to prioritize and compute the degree of sustainability of agricultural farmlands under the impacts of the lake drought. Figure 6 shows the computed spatial distribution of the results of the scenario-based SFP analysis. As this figure shows, the productivity of agricultural lands is expected to be reduced substantially due to the impact of soil and aquifer salinization. Results of this simulation indicated that the area of farmlands for SFP is subjected to be reduced significantly by both soil and aquifer salinization. As indicated, about 500,000 hectares of farmlands exist in the LUB. However, based on the environmental- and land suitability assessment (Fig. 6), about 375,000 hectares of the current farmland areas are contributing to SPF.Based on the simulation, about 29,100 hectares and 20,600 hectares will be impacted by aquifer and soil salinization, respectively. These numbers are anticipated to increase to 248,000 and 52,000 hectares by 2040 . The simulation shows even worse environmental conditions for 2050 when about 260,200 hectares $(69.4 \%)$ of highly productive farmlands will be affected by aquifer salinization. It is also anticipated that 132,420 hectares $(35.4 \%)$ of the highly productive farmlands will be directly impacted by soil salinization and lose their fertility for crop development by 2050. In addition, land subsidence will also increase significantly and affect the infrastructure and farmlands. These scenario-based numbers indicate that the LUB is going to face critical environmental conditions. While the LUB area currently produces $8.47 \%$ of the total food produced in Iran and feeds 7.3 million people, it is now clear that the region will face serious challenges in the coming decades.

\section{Discussion}

The results of this research indicated that degrading environmental conditions in the LUB will significantly impact the SFP. Our investigations show that mismanagement of water resources, the 
extension of the agricultural farmlands, and the excessive water extraction from aquifers have contributed to the lake drought and have led to problems, such as extensive land degradation and soiland water salinity, which threaten the SFP. The lack of sustainable development strategies and the mismanagement of the fragile ecosystem has contributed to these problems over the past three decades. Thus, plans and programs based on a sustainable development agenda are urgently needed to mitigate the anticipated food security crisis and associated socioeconomic and environmental problems. Such plans and programs should be designed and implemented according to the scientific evidence of environmental and socioeconomic factors and under consideration of the local characteristics of the LUB. They should be based on specific, realistic, measurable, practical, time-bound actions to bring about actual changes. It is also critical to develop decision-making approaches that can be optimized and improved by establishing feedback mechanisms to determine the valuable insights from unfulfilled outcomes $^{29}$.

According to our results, the agriculture system in the LUB is characterized by family farming (in small land lots) and is sustained based on the traditional irrigation system. A wide variety of high-water demand crops have been produced on this basis over the past decades based on farmers' choices and market demand. Due to the water salinization and land degradation trends, we call for a prompt sustainable agricultural policy that supports activities like precision agriculture and priorities crops with low water demand. In fact, we consider the modification of cropping patterns towards low water demand crops as one of the cheapest and most efficient solutions for reducing the overall agricultural water consumption. In addition, land readjustment and aggregation of small farms to develop a modern agriculture system would benefit farmers and reduce the irrigation water demand. Our land suitability analysis for low water demand and horticultural crops can support decision-makers and authorities in the agriculture sector in deciding on the presence or absence of a specific plant in the optimal cropping pattern. ${ }^{30}$

Considering the political circumstances (i.e., international sanctions), the rate of population growth, as well as the importance of the LUB for the national food production $(8.47 \%)$ and the progressive land degradation and water shortage, developing plans and programs for sustainable development in the LUB are urgently needed. In accordance with other studies, we consider SFP one of the most effective measures to mitigate the environmental impacts of lake drought. Sustainable agriculture development also requires suitable strategies for balancing the environmental, economic, and social dimensions of food and agriculture governance ${ }^{29}$. In this context, international policy guidelines such as 'agenda 2030', with its guidelines for ensuring SFP in light of the increasing global environmental challenges, shall support the decision-makers in improving the environmental and socioeconomic status of the LUB ${ }^{29}$.

\section{Methods}

The current research uses an integrated geoinformation approach, whereby we applied a fuzzy-objectbased image analysis (FOBIA) and spectral analysis to obtain a time series of LUCC and soil salinization monitoring. We used the SAR satellite images to detect the land subsidence from 2015 to 2020 . The 
GIScience spatiotemporal analysis was also applied for trend analysis of climate indicators, soil characteristics, and water resources to develop the sustainable food production map. The central aspect of the research methodology is explained in the following:

\section{Land Use/cover Mapping And Trend Assessment}

We processed Landsat time series satellite images for LUCC and soil salinization monitoring. To detect changes, we obtained the satellite images for July of 1990, 1995, 2000, 2005, 2010, 2015 and 2020. To obtain the most accurate results, we applied the integrated FOBIA approach to LUCC monitoring and mapping. Therefore, we applied a multi-resolution segmentation to obtain image objects. For a FOBIA classification, segmentation parameters are critical since they directly impact the size of image objects and the final classification results. Therefore, we estimated the scale parameter ${ }^{31}$ and performed the segmentation with the scale of 20 , a shape index of 0.6 , and a compactness value of 0.4 . We identified the primary land use/cover pattern of the LUB based on a comprehensive discussion with the authorities and decision-makers and through field work. We employed a FOBIA classification to derive the characteristics of the LUCC subclasses. The training data were collocated in field operations and from existing and historical LUCC and cadaster maps and aerial photography, which were available in both of the agricultural resource organizations of West- and East Azerbaijan Provinces (ARO-W/EAP). We used a total of 21000 points (3000 points for each study year) to identify the characteristics of each LUCC subclass and as training data for the FOBIA classification. We were able to identify the relevant object features based on the spectral and spatial characteristics of each LUCC subclass and evaluated their effectiveness for driving each LULC subclass by comparing the training data with the fuzzy membership value of each object feature based on the following equations:

o Spectral attributes/ Brightness

$\backslash \operatorname{varvec} B=\frac{1}{\mathrm{n}_{\mathrm{vis}}} \sum_{\mathrm{i}=1}^{\mathrm{n}_{\mathrm{vis}}} \overline{\mathrm{c}}_{\mathrm{i}(\mathrm{vis})}(1)$

Where $B$ is the mean brightness of an object and $\bar{C}_{i(v i s)}$ is the sum of all the mean brightnesses in the visible bands divided by the corresponding number of bands $\mathrm{n}_{\text {vis }}$

o Normalized Difference Vegetation Index (NDVI)

$\mathrm{TV}=$ mean NDVI

$\mathrm{f}($ Object $)=\left\{\begin{array}{l}\left.L C i f f(\text { Object }) \leq \mathrm{T}_{\mathrm{v}}\right) \\ \left.V A i f f(\text { Object })>\mathrm{T}_{\mathrm{v}}\right)\end{array} \mathrm{T}_{\mathrm{v}}^{\prime}=\frac{\text { meanNDVI }_{\mathrm{LC}}+\text { meanNDVI }_{\mathrm{VA}}}{2}(2)\right.$

$T_{v}^{\prime}$ is an average of the mean NDVI values for the candidate object of LUCC class and vegetated areas (VA). The NDVI, which has a value between -1.0 and +1.0 
Green Normalized Difference Vegetation Index (GNDVI)

GNDVI $=100 *(1+(([$ Mean band 4]-[Mean band 2] $) /([$ Mean band 4]+[Mean Layer 2] $)))(3)$

o Modified Normalized Differenced Water Index (MNDWI)

MNDWI $=100 *(1+(([$ Mean Band4] $-[$ Mean Band5] $) /([$ Mean Band4 $]+[$ Mean Band5] $)))(4)$

o Normalized Built-up Index (NDBI)

$\mathrm{NDBI}=([$ Mean band 5]-[Mean band 4])/([Mean band 5]+[Mean band 4]) $(5)$

o Soil Water Content Index (InfraRed Index)/ Soil Color Index

SWCI (IR) $=($ NIR- ETM7)/ (NIR + ETM7) (6)

$S C l=R-G / R+G$

o Normalized Built-up Index (NDBI)

$\mathrm{NDBI}=([$ Mean band 5]-[Mean band 4])/([Mean band 5]+[Mean band 4]) $(7)$

Salinity Index (SI)

o Normalized Difference Salinity Index

Salinity Index $(\mathrm{SI})=\left([\right.$ Mean Layer 1$] *[\text { Mean Layer 3] })^{\wedge} 0.5(8)$

NDSI=([Mean band 3]-[Mean band 4])/([Mean band 3]+[Mean band 4]) (9)

o Shape Rectangular

$1-\sqrt{\frac{\lambda_{\min }}{\lambda_{\max }}}(10)$

$\lambda_{\min }$ is the minimal eigenvalue

$\lambda_{\max }$ is the maximal eigenvalue

$\frac{\left\{\#(x, y) \epsilon P_{v}: \rho v(x, y \rho) \leq 1\right\}}{\# P_{v}} P_{v}=(\mathrm{x}, \mathrm{y})$ is the elliptic distance at a pixel $(\mathrm{x}, \mathrm{y})(11)$

$[0,1]$; where 1 is a perfect rectangle

o Shape Index

$\frac{\mathrm{B}_{\mathrm{v}}}{4{\sqrt{\# \mathrm{v}_{\mathrm{v}}}}}$ 
$\mathrm{B}_{\mathrm{v}}$ is the image object border length

$4 \sqrt{\#_{\mathrm{p}_{\mathrm{v}}}}$ is the border of square with area of $\# P_{v}$

After identifying the relevant object-based features for LUCC classification, we exported the computed membership values for all objects in LUB to Python for the deep learning classification and to produce the final LUCC map. To validate the results, we applied an accuracy assessment based on the fuzzy synthetic evaluation (FSE), which was proposed by Feizizadeh ${ }^{32}$ and acknowledged for its effectiveness in FOBIA classifications by several studies ${ }^{3,33}$. Technically, the FSE makes use of two sets of data, namely reference data (ground truth data) and the results of the OBIA-based classification map. The FSE is used to compute the interpretation of confidence ratings (ICR), which is the classification confidence and observed level of error for each class ${ }^{33}$ (See supplementary Table 2 ). Therefore, $30 \%$ of all ground control points (6300 out of 21000) were used as references data, and the overall accuracy for the study period of 1990-2020 with 5-year intervals was computed to be $0.94,0.93,0.98,0.95,0.96,0.93$ and 0.97, respectively (See supplementary Table 3-4 for results of accuracy assessment based on the FSE).

\section{Land Degradation Monitoring (Soil Salinity And Land Subsidence)}

We used the obtained Landsat images to carry out a LUCC classification to monitor and map soil salinization. According to earlier studies, the spectral properties of Landsat allow us to compute the soil salinization rate based on the soil salinity indices ${ }^{34-35}$. The soil characteristics are impacted by various factors (e.g., vegetation cover, moister, texture, parent material, etc.), which must be considered in soil salinity mapping ${ }^{36-37}$. Therefore, we applied the Combined Spectral Response Index (CSRI) technique to compute the soil salinity ratio for each study year. The CSRI method was developed by Fernandez-Buces et. al ${ }^{38}$ and has been confirmed to be an efficient method for determining soil salinity by the remote sensing community ${ }^{37,39-40}$. The CSRI is based on the spectral information of RGB and the near-infrared bands, and it is computed as follows:

$\mathrm{CSRI}=\frac{\mathrm{B}+\mathrm{G}}{\mathrm{R}+\mathrm{NIR}} \times \mathrm{NDVI}$ and $(\mathrm{B}+\mathrm{G}) /(\mathrm{R}+\mathrm{NIR}) \times \mathrm{NDVI}(14)$

NIR: Near infrared and NDVI: Normalized Differences Vegetation Index

We used the field observation data together with the soil electrical conductivity (SEC) data to validate the results. Time series SEC data were obtained from the ARO-W/EAPs. In order to validate the results, a linear regression analysis was applied to compute the spatial correlation between the reference data and the results of the CSRI method for each study year. The result of the linear regression analysis from 1990-2020 with 5-year intervals was computed to be $0.93,0.92,0.90,0.92,0.96,0.97$ and 0.95, 
respectively, which represents a very high spatial correlation between the reference data and the obtained soil salinization maps.

As indicated in the context of land degradation, we also aimed to monitor the land subsidence in the LUB. We applied differential interferometric synthetic aperture radar analysis (DInSAR) for the 2015-2020 period to create a land subsidence map. The DInSAR technique is a reliable and fast approach to derive long- and short-term deformations. The technique mainly relies on the 'master' and 'slave' SAR image processing of the same part of the earth from the same satellite orbit. In the repeated pass, the difference of phase value correlation of two SAR images can be used to estimate the ground subsidence. Generally, the phase correlation or coherence 0 of two acquisitions in DInSAR analysis contains various sources. After reducing non-deformation phases, such as the atmospheric phase, topographic phase, and noises, the multi-temporal DInSAR can be implemented. In the multi-temporal analysis, images are taken at different times $\left(T_{1}, T_{2}, \ldots, T^{n}\right)$, and the phase value of the image is a simple way to measure the changes

in satellite-to-target direction $\left(R_{1}, R_{2}, \ldots, R_{n}\right)$ across the same study area ${ }^{41-43}$. For the DInSAR analysis, we used 6 single look complex (SLC) images of descending orbits (T 79) of Sentinel-1 to cover the study area. The images were taken on the 2015.11.11, 2017.11.12, and 2020.11.02, and cover the upper and lower parts of the Lake Urmia basin (6 images in total) in interferometric wide (IW) mode. The images are in VV (vertical - vertical) and VH (Vertical - horizontal) polarizations, and the incidence angle of the images are $39.08^{\circ}$. The incidence angle difference of the first pair (2015.11.11 and 2017.11.12) and the second pair (2017.11.12 and 2020.11.02) are $0.009^{\circ}$ and $0.01^{\circ}$, respectively. Due to the semi-arid to arid climate in the study area, the large temporal baseline ( 2 years) is not a serious problem for the interferometric analysis, which has also been acknowledged in similar studies ${ }^{21-24}$.

\section{Water Salinization Spatiotemporal Analysis}

The significance of freshwater for agricultural-, industrial-, and residential purposes is beyond debate. Due to the semi-arid climate in the LUB, agricultural activities were traditionally based on surface run-off water and groundwater. The LUCC results reveal a substantial increase in croplands and farmland over the past 30 years, which predominantly depend on groundwater. The regional water organizations in both West and East Azerbaijan Provinces (RWO-E/WAPs) have monitored the LUB water quality parameters annually since 2000 and quarterly since. We made use of observations from deep- and semi-deep wells, springs, and Qanats during the wet and rainy seasons. Since the number of observation wells has increased every year since the Lake Urmia drought, the groundwater observation data used in the spatiotemporal modelling of the groundwater quality assessment was limited to 630 in 2005, 684 in 2010,751 in 2015, and 859 in 2020 . We obtained and analyzed the following water quality parameters for the studied time period (2000-2020): electrical conductivity (EC), power of hydrogen (pH), potassium $(\mathrm{K}+)$, total hardness $(\mathrm{TH})$, sulfate (SO42-), magnesium (Mg2+), chloride $(\mathrm{Cl}-)$, sodium $(\mathrm{Na}+)$, total dissolved solids (TDS), calcium (Ca2+), carbonate (CO32-), and bicarbonate (HCO3-). We obtained groundwater physicochemical data and evaluated the water status using the water quality index (WQI), spearman correlation, principal component analysis (PCA), and agglomerative hierarchical clustering 
(ACA) based on the GIS spatial analysis for determining the hydro-geochemical attributes. The statistical evaluation of the physicochemical groundwater parameters is essential to comprehend the main factors controlling water quality variations over time ${ }^{44}$.

Multivariate statistical techniques such as the PCA are effective approaches for data visualizing and mining. A PCA technique was used to identify correlations between physical and chemical characteristics in the aquifer and to elucidate complicated patterns in data matrices ${ }^{45-46}$. Squared cosines with absolute values of more than or equal to 0.4 were used for the exploration of the observed ions ${ }^{46-47}$. We used the Spearman correlation coefficient to identify the sources of different elements in the groundwater samples. High coefficients reveal the significance of the relationship between two parameters. A positive coefficient indicates that the associated parameters are similar and harmonious, while a negative coefficient indicates that the variables are moving in opposite directions. We carried out an agglomerative hierarchical cluster analysis (ACA) of the groundwater data to identify a specific pattern of similar observations within the studied variables ${ }^{46}$. The ACA allowed us to identify suitable structures in chaotic and complex data and thus simplify the explanation of observations ${ }^{48}$. Using a GIS spatial analysis, we obtained the distribution characteristics and created the groundwater quality maps. While many interpolation methods are available, we choose to use the inverse distance weighted (IDW) interpolation technique, which is the most frequently used deterministic modelling tool ${ }^{49}$. The model is based on the hypothesis that a node shares more similarities with nearby points and that it is influenced more strongly by the surrounding data values. We used 856 points and derived the node values by averaging the weighted total of all of them.

\section{Environmentally sustainable food production mapping}

We applied a GIS-based multi criteria decision analysis (GIS-MCDA) to multiple factors of food production in the LUB to examine sustainable food production under the impact of the Lake Urmia drought. Sustainable food production in a fragile ecosystem such as the LUB must consider the interaction of several causal spatial indicators. The GIS-MCDA provides an effective approach for dealing with the spatial decision problems and patterns based on the concept of 'spatial thinking' ${ }^{50-51}$. The GISMCDA allows us to consider the relevant spatial indicators and their characteristics as attributes in combination with decision maker's preferences to analyze the spatial problems ${ }^{51}$. In this research, we analyzed sustainable food production in the LUB by considering the relevant causal climate indicators affecting agricultural production, namely annual average precipitation, temperature, sunshine hours, and humidity. In the context of soil characteristics, the soil degradation, fertility, texture, and depth were also used as causal indicators. From the land characteristics perspective, the salt scattering spots and land use/cover were also considered as relevant indicators for SFP (See Supplementary Fig. 6). The selection of these causal indicators is based on expert opinions, data availability, and relevant research literature $29,52-53$. 
After finalizing the causal environmental indicators, the initial data were collected from the relevant governmental departments, satellite images, and the Spatial Data Infrastructure (SDI) of LUB. All data were gathered, relevant geometric edits were applied, and the indicators were developed into a spatial GIS dataset. Since the spatial GIS data were collected from heterogeneous resources with different scales, we used the fuzzy standardization process to standardize the indicators in the same scale suited for criterion weighting. This approach considers the degree of fuzzy membership values on a scale of $0-1$ based on the benefit/ cost context of the indicators ${ }^{49}$. In the GIS-MCDA analysis, the significance of each criterion is computed as part of the decision analysis. We employed the Fuzzy Analytical Network Analysis (FANP) to determine the significance of each indicator. The FANP is an efficient GIS-MCDA weighting tool ${ }^{50}$. We included the knowledge of 35 experts from different departments of the University of Tabriz and the University of Urmia. We asked these experts from agricultural-, natural resource-, and food security departments to initially rank the provided indicators. Then, based on the FANP method, we yielded the following criteria weights: precipitation (0.098), temperature (0.096), sunshine hours $(0.075)$, humidity (0.058), groundwater depth (0.071), water quality $(0.095)$, soil degradation $(0.069)$, soil fertility $(0.098)$, soil texture (0.099), soil depth (0.098), salt scattering spots (0.086), and land use/cover (0.098). For the criteria weighting, it is necessary to compute the consistency ratio (CR) to validate the obtained weights.

According to Saaty ${ }^{54}$, a $\mathrm{CR}<0.1$ indicates an acceptable level of consistency among the experts and that the results can be employed for a spatial aggregation. Our study yielded an acceptable CR value of 0.065 .

Criteria weighting in GIS-MCDA significantly influences the uncertainty and reliability of the results ${ }^{55}$. Therefore, we applied a global sensitivity analysis (GSA) to determine the validity of the computed weights using the FANP method. The GSA approach is used to compute the two critical indexes of $S$ (first order) and $S t$ (total effect). The letters $S$ and $S t$ denote that the FANP's weights were assigned in a semantic manner. Any discrepancy in the value and order of the $S$ and $S t$ indices, as well as the reference weights (e.g. FANP's weights), can be regarded as uncertainty connected with the criteria weights ${ }^{56}$. Accordingly, we used a 'weighted overlay' spatial aggregation function to produce the food production capability map.

\section{Environmental Prediction Based On The Ca-markov}

We used a combination of a Markov model and a Cellular Automata model (CA-Markov) to predict the land degradation and water salinity based on the trend observed in the past years (1990-2020). Both techniques have been identified as being effective techniques for GIScience prediction problems ${ }^{57}$. A typical CA-Markov model separates the discrete cellular, finite state, neighbor, and rule features into four categories while analyzing the trend as follows:

$$
Z_{(I+1)}=Z_{(I)} \times Q
$$

15

Page $14 / 25$ 
$Z(I)=$ the first map in year $A l, Z(I+1)=$ the second map year $B, I+1, Q=$ state transition matrix, and $Z$ can be described as the following matrix:

$\mathrm{Z}=[\mathrm{Z} 1 \mathrm{Z2} \mathrm{Z3}](16)$

$Z i(i=1,2,3)$ represents the changes between classes of map $A$ and $B, Q$ can be described as an $[n, n]$ matrix in the following, where $n=$ total number of changes between map $A$ and $B, Q i j=$ transition probability for any changes between map $A$ and $B$ from the time line of $i$ to $j$, and the sum of each row of the matrix should be equal to 1 .

$$
Q=\left[\begin{array}{cccc}
Q_{11} & Q_{12} & \ldots & Q_{1 n} \\
Q_{21} & Q_{22} & \ldots & Q_{2 n} \\
\vdots & \vdots & \vdots & \vdots \\
Q_{n 1} & Q_{n 2} & \ldots & Q_{n n}
\end{array}\right], \sum_{(j=1)}^{n} Q_{i j}=1,1 \leq i, j \leq n, n=4
$$

17

According to a transformation function, the next state cell is decided by the current state and its surroundings ${ }^{57-58}$. This method is based on generating a transition probability matrix between two maps in different timelines. The transition probability matrix enables an assessment that indicates the likelihood of each pixel in class A of the first map class converting to another class (e.g. B, C, D, ...) or remaining in class $A$ in the second map class ${ }^{59}$. The Markov chain, which is technically a separate random process, uses transition probability to forecast the next state and all future states based on the current state ${ }^{60}$. Except for some of the after-effect occurrences, it is a viable method for predicting regional characteristics. We used CA-Markov to predict the land use/cover, soil, and water salinization maps for 2030, 2040, and 2050 based on the trend obtained for each environmental indicator.

\section{Spatial Uncertainty Analysis}

Understanding the spatial uncertainty is critical in geospatial analysis and modelling. Data quality, correctness, inaccuracy, vagueness, fuzziness, and imprecision, are all referred to as spatial uncertainty in GIScience ${ }^{32}$. Uncertainty in GIS-based modelling is inevitable due to the variety caused by a heterogeneous dataset, expert opinions, and model error, which has forced the GIScience community to develop spatial and statistical approaches to understand and quantify uncertainty ${ }^{60}$. The Dempster Shafer Theory (DST) has been identified as an efficient technique for spatial uncertainty analysis. It is based on mathematical operations employing Bayesian probability theory ${ }^{3}$. The DST's features make it an effective tool for modeling the imprecision and computing the spatial uncertainty ${ }^{60}$. The DST can compute the epistemic uncertainty that affects expert knowledge of the probability $\mathrm{P}\left(\mathrm{M}_{-}\right)$within the alternative model $M_{-}=1, \ldots, n$. This is also known as the 'theory of evidence', which aims to compute the BBA $m(A)$ on sets $A$ (the focal sets) of the power set $P(Z)$ of the event space $Z$, i.e., on sets of outcomes 
rather than single elementary events ${ }^{60}$. The belief function computes the lower limit value for a (known) probability to determine the spatial uncertainty. The plausibility function additionally predicts the upper bound value for an (unknown) probability. The geographic uncertainty can be calculated using the difference between the plausibility $(P l)$ and belief $(B e l)$ functions. We employed the Belief function in Idrisi software to calculate DST and to define the spatial uncertainty of the predicted soil and water salinization maps for 2030, 2040, 2050 as well as the computed sustainable food production map (See Supplementary Fig. 7).

$$
m: P(Z) \rightarrow[0,1], m(0)=0 ; \sum_{A \in(\mathrm{Z})} m(A)=1(18)
$$

\section{Declarations}

\section{Data availability}

The data that support the findings of this study are available on request from the corresponding author.

\section{References}

1. Sterner, S. W., Keeler, B., Polasky, S., Poudel, R.\& Rhude, K, Ecosystem services of Earth's largest freshwater lakes, Ecosystem Services, org/10.1016/j.ecoser.2019.101046 (2020).

2. Perkins, , The rise and fall of the world's largest lake, Earth, Oceanography, doi:10.1126/science.abj8351 (2021)

3. Feizizadeh, B., Kazamei, Garajeh, M., Blaschke, T.\& Lakes, T., A deep learning convolutional neural network algorithm for detecting saline flow sources and mapping the environmental impacts of the Lake Urmia drought in Iran, Catena, 105585 (2021)

4. Sustainable Development Goals Report (United Nations Publications, 2019).

5. UN: United Nation, 2019, World Population Prospects (United Nations Publications, 2019).

6. Golay, C., The Food Crisis and Food Security: Towards a New World Food Order?, International development policies, https://doi.org/10.4000/poldev.145,(2010)

7. Helmi Ali, M., Suleiman. N., Sustainable food production: Insights of Malaysian halal small and medium sized enterprises, Int. J. Production Economics, 181, 303-314 (2016)

8. Ververs, M. T. The East African food crisis: did regional early warning systems function? The Journal of nutrition, 142(1), 131-133, (2012)

9. IMA: Iranian Ministry of Agriculture, annual report of Iranian agricultural activities, https://www.maj.ir (2021)

10. National Statistics Center of Iran, Results of national census for population density, amar.org (2016)

11. Abbaspour, M., Javid, H.A., Mirbagheri, S.A., Ahmadi Givi, F., Moghimi, P, Investigation of lake drying attributed to climate change, Int. J. Environ. Sci. Technol. 9:257-266 (2012) 
12. Goudarzi, M., Salahi, B.\& Hoseini, A., Study on Effects of Climate Changes on Surface Runoff Changes Case Study: Lake Urmia Basin,Ecohydrology, 2(2), 175-189 (2015)

13. Azizi, Gh, Nazif, S., Abbasi, F, An assessment of the influence of climate change on the Lake Urmia's water level reduction, Journal of Interdisciplinary Studies in the Humanities, 9 (4), 1-21 (2017)

14. Mansouri Daneshvar, M.R., Ebrahimi, M.\& Nejadsoleymani, H, An overview of climate change in Iran: facts and statistics, Environmental System Research, org/10.1186/s40068-019-0135-3 (2019)

15. Mosaffa, M., Nazif, S., Amirhosseini, Y. K., Balderer, W., \& Meiman, H. M. An investigation of the source of salinity in groundwater using stable isotope tracers and GIS: A case study of the Lake Urmia basin, Iran. Groundwater for Sustainable Development, 100513 (2020)

16. Kazemi Garajeh, M., Malaky, F., Weng, Q., Feizizadeha, B., Blaschke,\& Lakes, T., An automated deep learning convolutional neural network algorithm applied for soil salinity distribution mapping in Lake Urmia, Iran, Science of The Total Environment, doi.org/10.1016/j.scitotenv.2021.146253 (2021)

17. Ghosh, D., Karmakar, M., Banerjee, M., \& Mandal, M. Evaluating the rate of change and predicting the future scenario of spatial pattern using Markov chain model: a study from Baghmundi CD Block of Purulia district, West Bengal. Applied Geomatics, 1-12 (2020)

18. Butt, A., Shabbir, R., Ahmad, S. S., \& Aziz, N. Land use change mapping and analysis using Remote Sensing and GIS: A case study of Simly watershed, Islamabad, Pakistan. The Egyptian Journal of Remote Sensing and Space Science, 18(2), 251-259 (2015).

19. Mondal, P. P., \& Zhang, YResearch progress on changes in land use and land cover in the western Himalayas (India) and effects on ecosystem services. Sustainability, 10(12), 4504 (2018)

20. Perani, Z, simulation the impacts of Lake Urmia causeway on the hydrodynamic crucial and lake drought, master thesis, University of Urmia, Urmia, Iran (2016)

21. Karimzadeh, S.; Matsuoka, M. Remote Sensing X-Band SAR Data for Land Subsidence and Pavement Monitoring. Sensors 20, 4751 (2020),

22. Karimzadeh, S.; Matsuoka, M. Ground Displacement in East Azerbaijan Province, Iran, Revealed by Lband and C-band InSAR Analyses. Sensors 20, 6913 (2020)

23. Nadiri,A., Khatibi,R., Khalifi, P., Feizizadeh, B., A study of subsidence hotspots by mapping vulnerability indices through innovatory 'ALPRIFT'using artificial intelligence at two levels, Bulletin of Engineering Geology and the Environment, 79, 3989-4003. (2020)

24. Karimzadeh, S. Characterization of land subsidence in Tabriz basin (NW Iran) using InSAR and watershed analyses. Acta Geod. Geophys. 51, 181-195 (2016)

25. Javad Anbari, M., Zarghami,M., Nadiri. A., An uncertain agent-based model for socio-ecological simulation of groundwater use in irrigation: A case study of Lake Urmia Basin, Iran, Agricultural Water Management, doi.org/10.1016/j.agwat.2021.106796 (2021)

26. Hemmati, Ahmadi, H., Hamidi, S., Naderkhanloo, V., Environmental effects of the causeway on water and salinity balance in Lake Urmia, Regional Studies in Marine Science, doi.org/10.1016/j.rsma.2021.101756 (2021) 
27. ULRP: Lake Urmia Restoration Program, Annual report for progress of Lake Urmia restoration programs, center for strategic researches, 2020.

28. Azizi, G., Nazif, S.\& Abbasi, F., An assessment of the contribution of Climate change to Lake Urmia's water level reduction, Journal of Interdisciplinary Studies in the Humanities, 9(4), 1-21 (2017)

29. Movilla-Pateiro, L., Mahou-Lago, X. M.\& Doval, M. I., Simal-Gandara, J., Toward a sustainable metric and indicators for the goal of sustainability in agricultural and food production, Critical Reviews in Food Science and Nutrition, 61:7, 1108-1129, DOI: 10.1080/10408398.2020.1754161(2021)

30. Vafabakhsh, J., Mohammadzade, A., Bazargan, K., Navidi, M., N., Comparative Study of Cropping Pattern and Land Suitability of Major Horticultural and Field Crops in the Lake Urmia Basin, Journal of Agroecology, 11 (3), 755-805 (2018)

31. Drăguţ, L., Tiede, D., Levick. R., ESP: a tool to estimate scale parameter for multiresolution image segmentation of remotely sensed data. International Journal of Geographical Information Science, 24 (6), 859-871 (2010)

32. Feizizadeh, B., A Novel Approach of Fuzzy Dempster-Shafer Theory for Spatial Uncertainty Analysis and Accuracy Assessment of Object-Based Image Classification, IEEE Geoscience and Remote Sensing Letters, 15 (1), 18-22 (2018)

33. Feizziadeh, B., Blaschke, T., Tiede, D., Rezaei Moghaddam, H.M., Evaluation of fuzzy operators within an Object-Based Image Analysis Approach for Landslide change detection analysis, Geomorphology, 293, 240-254 (2017)

34. Waqasa, M. M., Niaza, Y., Alib, S., Ahmadc, I., Fahadd, M., Rashide, H., Awanf, U. K. Soil salinity mapping using satellite remote sensing: A case study of lower Chenab canal system, Punjab, Earth Sciences Pakistan 4(1): 07-09 (2020)

35. Camera, C., Zomeni, Z., Noller, J. S., Zissimos, A. M., Christoforou, I. C., \& Bruggeman, A. A highresolution map of soil types and physical properties for Cyprus: A digital soil mapping optimization. Geoderma, 285, 35- 49 (2017)

36. Shi, X., Jianghui, S., Haijiang, W., Xin, Lv., Monitoring soil salinization in Manas River Basin, Northwestern China based on multi-spectral index group, European Journal of Remote Sensing, 54 (2), 176-188 (2021).

37. Fernandez-Buces., N., C. Siebe, S. Cram, J.L. Palacio, Mapping soil salinity using a combined spectral response index for bare soil and vegetation: A case study in the former lake Texcoco, Mexico. Journal of Arid Environments, 65; 644- 667 (2006)

38. Nguyen, K., Liou, Y., Tran, H., Hoang, P., Nguyen, T.H., Soil salinity assessment by using nearinfrared channel and Vegetation Soil Salinity Index derived from Landsat 8 OLI data: a case study in the Tra Vinh Province, Mekong Delta, Vietnam, Progress in Earth and Planetary Science, doi.org/10.1186/s40645-019-0311-0 (2020)

39. Alqasemi, A.S., Ibrahim, M., Fadhil, A., Ayad M., Saibi, H, Fugara,A., Gordana.K., Detection and modeling of soil salinity variations in arid lands using remote sensing data, Open Geosciences, 13 (1), 443-453 (2021) 
40. Massonnet, D., Fiegl, K.L., Radar interferometry and its application to changes in the earth's surface. Reviews of Geophysics 36 (4), 441-500 (1998)

41. Massonnet, D., Rossi, M., Carmona, C., Adragna, F., Peltzer, G., Feigl, K., Rte, T., The displacement field of the Landers earthquake mapped by radar interferometry. Nature 364, 138-142 (1993)

42. Zebker, H.A., Rosen, P.A., Hensley, S., Atmospheric effects in interferometric synthetic aperture radar surface deformation and topographic maps. Journal of Geophysical Research 102 (2), 7547-7563) 1997(

43. Jeon, C., Raza, M., Lee, J. Y., Kim, H., Kim, C. S., Kim, B., Kim, J. W., Kim, R. H., LEE, S. W., Countrywide Groundwater Quality Trend and Suitability for Use in Key Sectors of Korea. Water, 12 (4), 1193 (2020)

44. Adeogun, A. O., Babatunde, T. A., Chukwuka, A. V. Spatial and temporal variations in water and sediment quality of Ona river, Ibadan, Southwest Nigeria. European Journal of Scientific Research, 74, 186-204 (2012)

45. Abdollahi, Z., Kavian, A., Sadeghi, S. H. R., Khosrovyan, A., Delvalls, A. Identifying environmental risk associated with anthropogenic activities in Zanjanrud River, Iran, using an integrated approach. Catena, 183, 104156 (2019)

46. Khosrovyan, A., Delvallst, T., Riba, I, Effects of simulated CO 2 escape from sediments on the development of midge Chironomus riparius. Aquatic toxicology, 156, 230-239 (2014)

47. Bhat, S. A., Meraj, G., Yasern, S., Pandit, A. K. Statistical assessment of water quality parameters for pollution source identification in Sukhnag stream: an inflow stream of lake Wular (Ramsar Site), Kashmir Himalaya. Journal of Ecosystems, (2014)

48. Ma, L., Qian, J., Zhao, W., Curtis, Z., Zhang, R. Hydrogeochemical analysis of multiple aquifers in a coal mine based on nonlinear PCA and GIS. Environmental Earth Sciences, 75, 716 (2016)

49. Goodchild, F.M., Spatial Thinking and the GIS User Interface, Procedia Social and Behavioral Sciences 21, 3-9 (2011)

50. Malczewski, J., \& Rinner, C. Multicriteria decision analysis in geographic information science (p. 331). New York: Springer. (2015)

51. Mohamed,E.S., Saleh, A.M.\& Belal, A.A., Sustainability indicators for agricultural land use based on GIS spatial modeling in North of Sinai-Egypt, The Egyptian Journal of Remote Sensing and Space Science, 17 (1), 1-15 (2014)

52. Moragues-Faus, A., Marceau, A., Measuring Progress in Sustainable Food Cities (2019)

53. García-Oliveira, P., Fraga-Corral,M., Pereira, A.G, Prieto, M.A., Simal-Gandara, J., Solutions for the sustainability of the food production and consumption system, Critical Reviews in Food Science and Nutrition, org/10.1080/10408398.2020.1847028 (2020)

54. Saaty, T.L. and Vargas, L.G. Decision Making with the Analytic Network Process: Economic, Political, Social and Technological Applications with Benefits, Opportunities, Costs and Risks, New York: Springer (2006) 
55. Ligmann-Zielinska, A., Jankowski, P., Spatially-explicit integrated uncertainty and sensitivity analysis of criteria weights in multicriteria land suitability evaluation, Environmental Modelling \& Software, 57, 235-247 (2014)

56. Ligmann-Zielinska, A., Jankowski, P., Spatial uncertainty and sensitivity analysis for multiple criteria land suitability evaluation, Journal of Geographical Systems, 13, 2-15 (2012)

57. Eastman, J.R .IDRISI guide to GIS and image processing Accessed in IDRISI Selva 17, Worcester, Clark University, 182-185, (2009)

58. Guan, D., Gao, W., Watari, K., \& Fukahori, H. Land use change of Kitakyushu based on landscape ecology and Markov model. Journal of Geographical Sciences, 18(4), 455-468 (2008)

59. Li, L., Ban, H., Wechsler, S.P.\& Xu, B., Spatial Data Uncertainty. In: Huang, B. (Ed.), Comprehensive Geographic Information Systems., 1, 313-340 (2018)

60. Liu, Z., Pan Q., Dezert J., Hybrid Classification System for Uncertain Data. IEEE Transactions on Systems, Man, and Cybernetics: Systems, DOI. 10.1109/TSMC.2016.2622247 (2016)

\section{Figures}




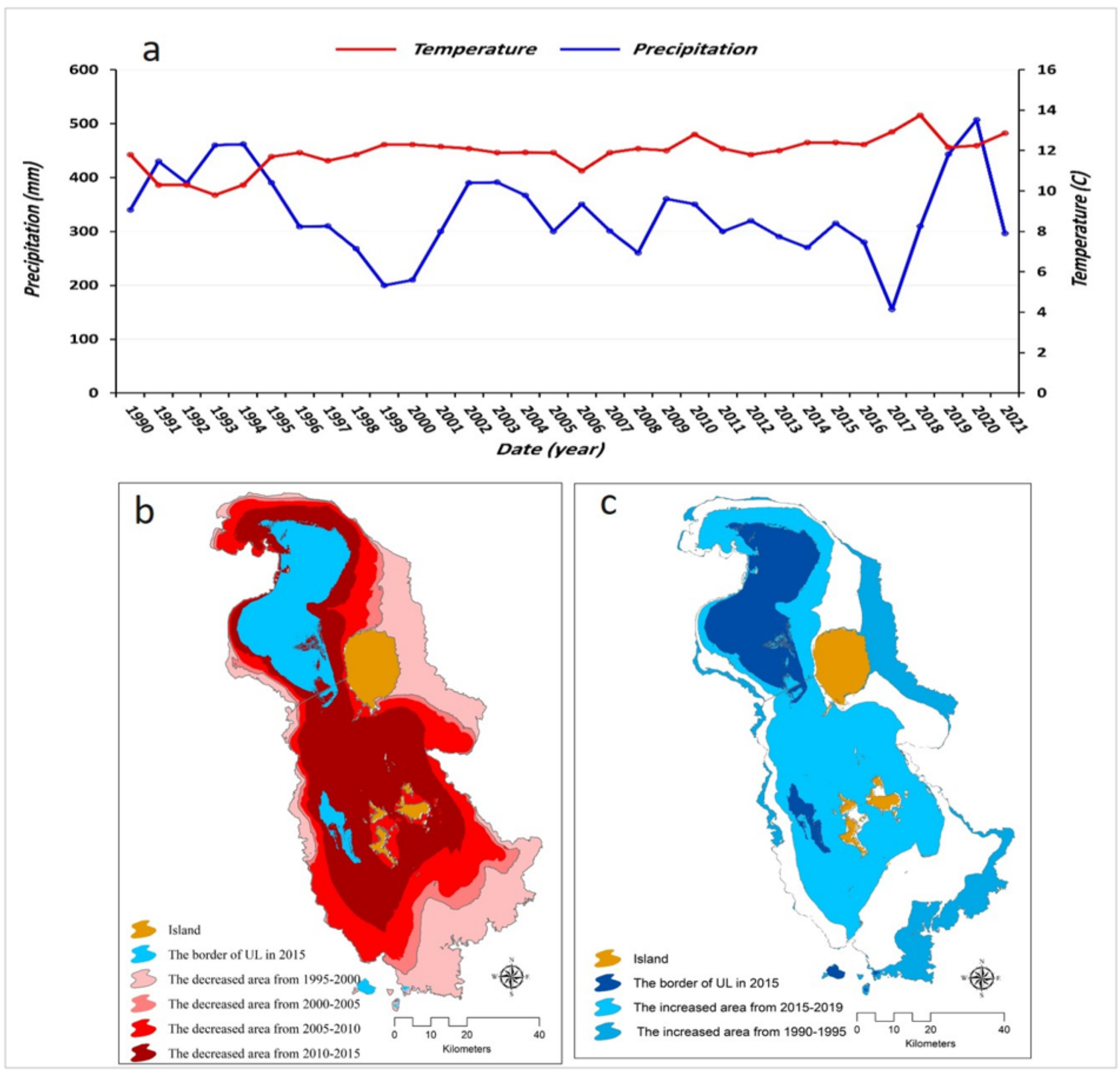

\section{Figure 1}

Trend of AAP, AAT, and the changes in surface area of Lake Urmia between 1990 and 2020 政

Figure 2

Results of the LUCC monitoring in the LUB from 1990 to 2020 
(a)
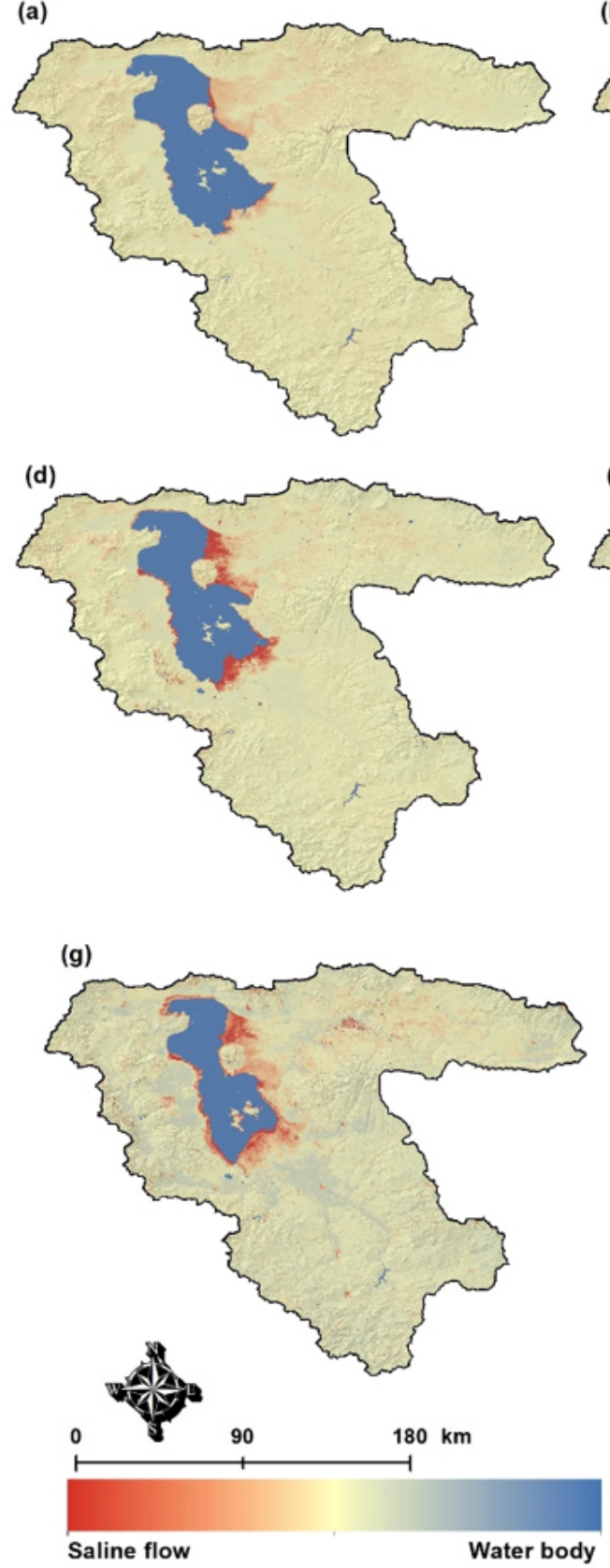

(b)

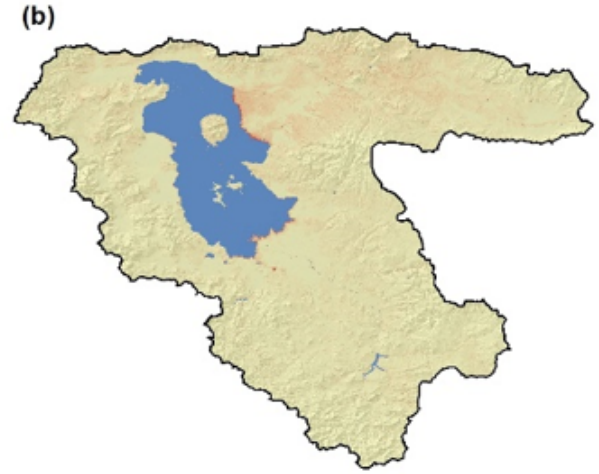

(c)
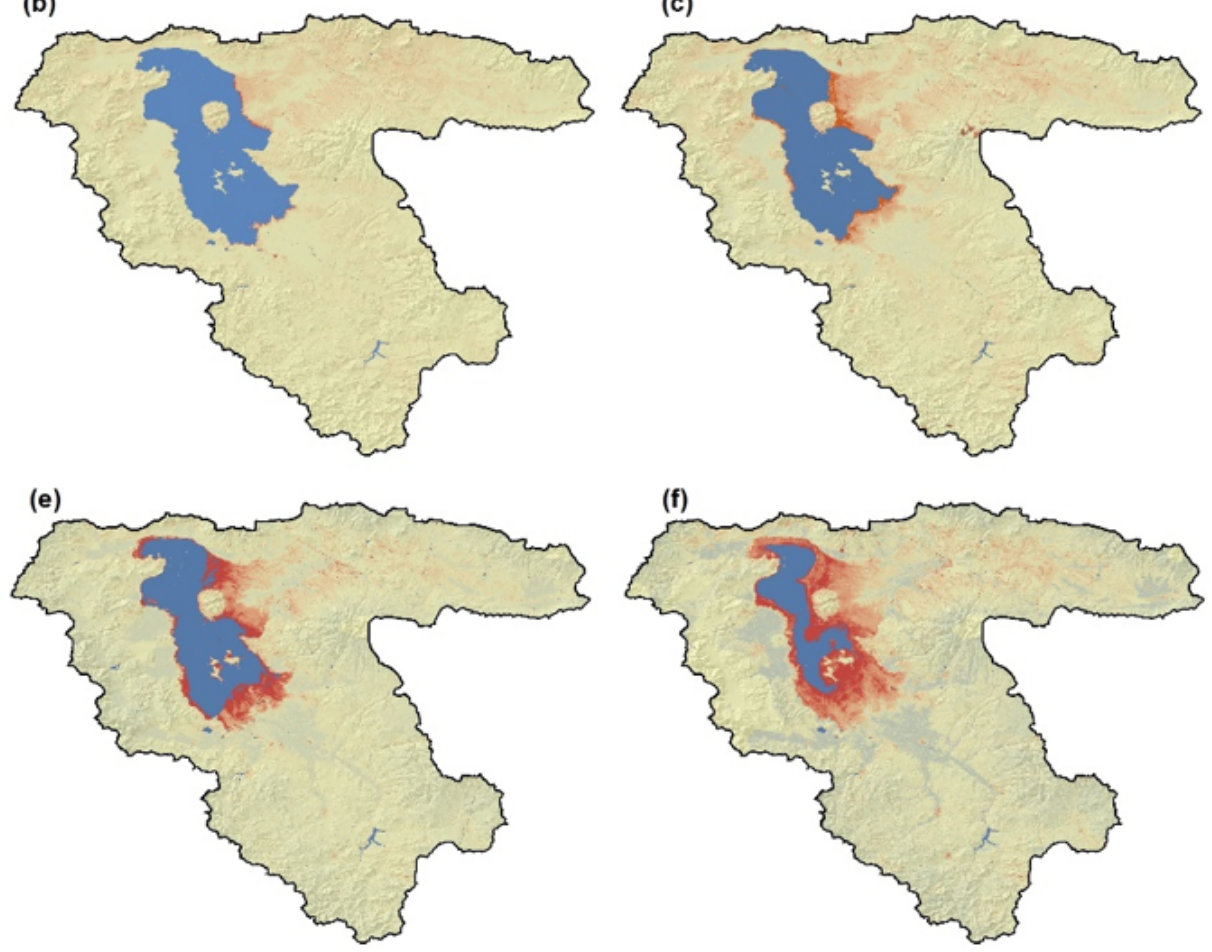

(h)

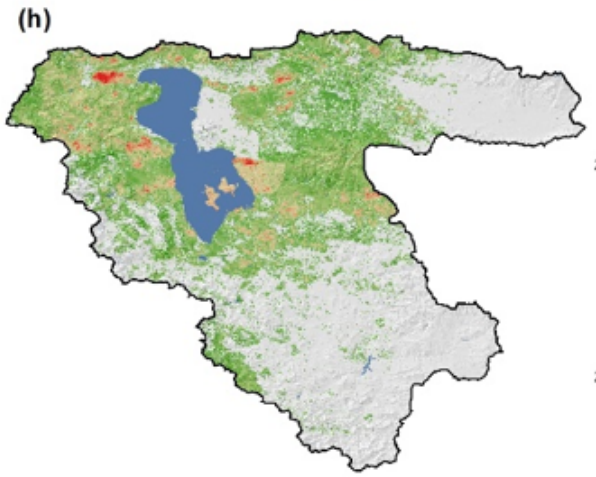

Land Subsidence

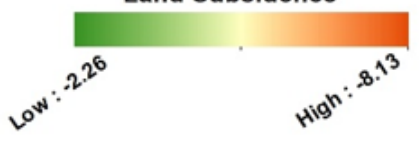

(i)

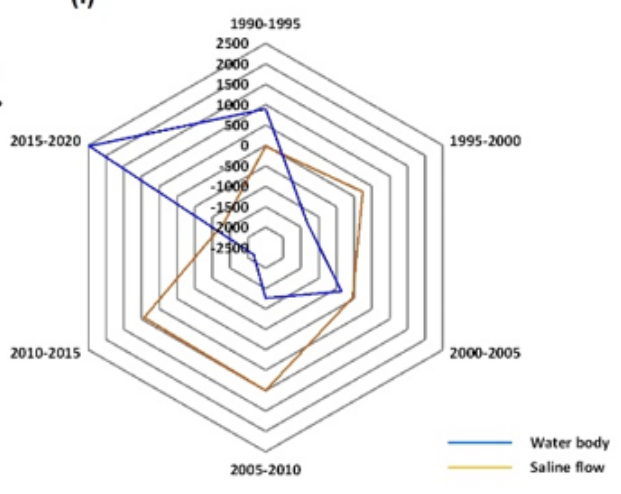

\section{Figure 3}

Results of the soil salinization from 1990-2020 (a-g) and land subsidence (i) in the LUB 

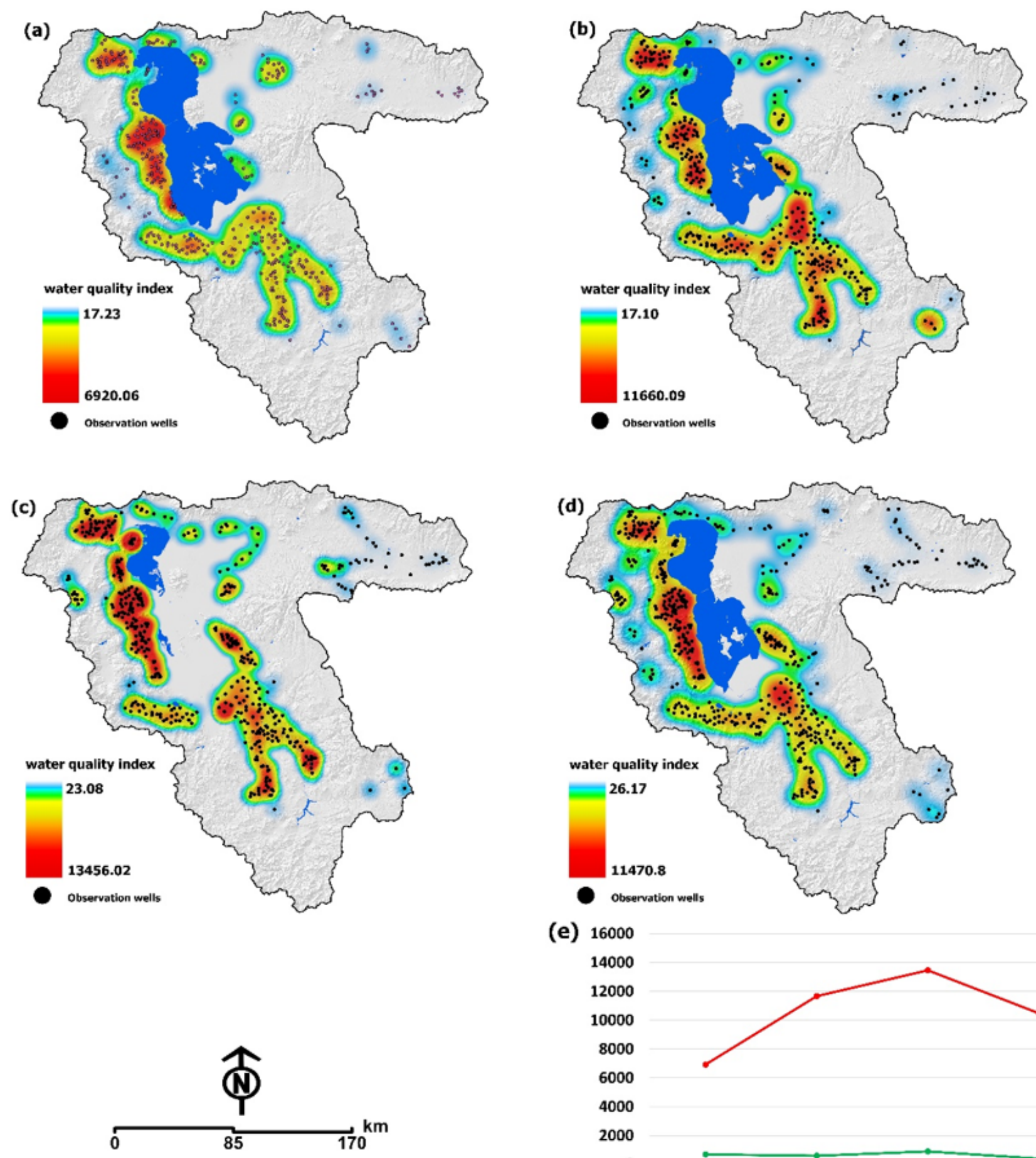

(e) 16000

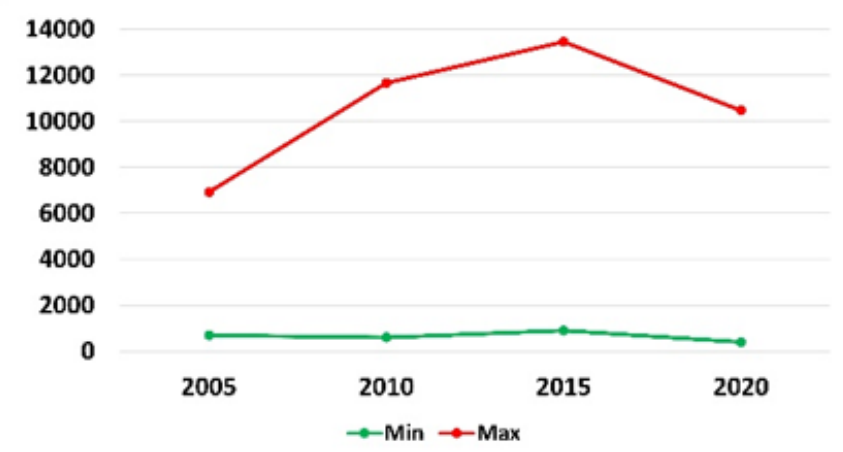

\section{Figure 4}

Results of groundwater quality assessment based on the observation data including: a)2000, b)2005, c0 2010 and d) 2020 

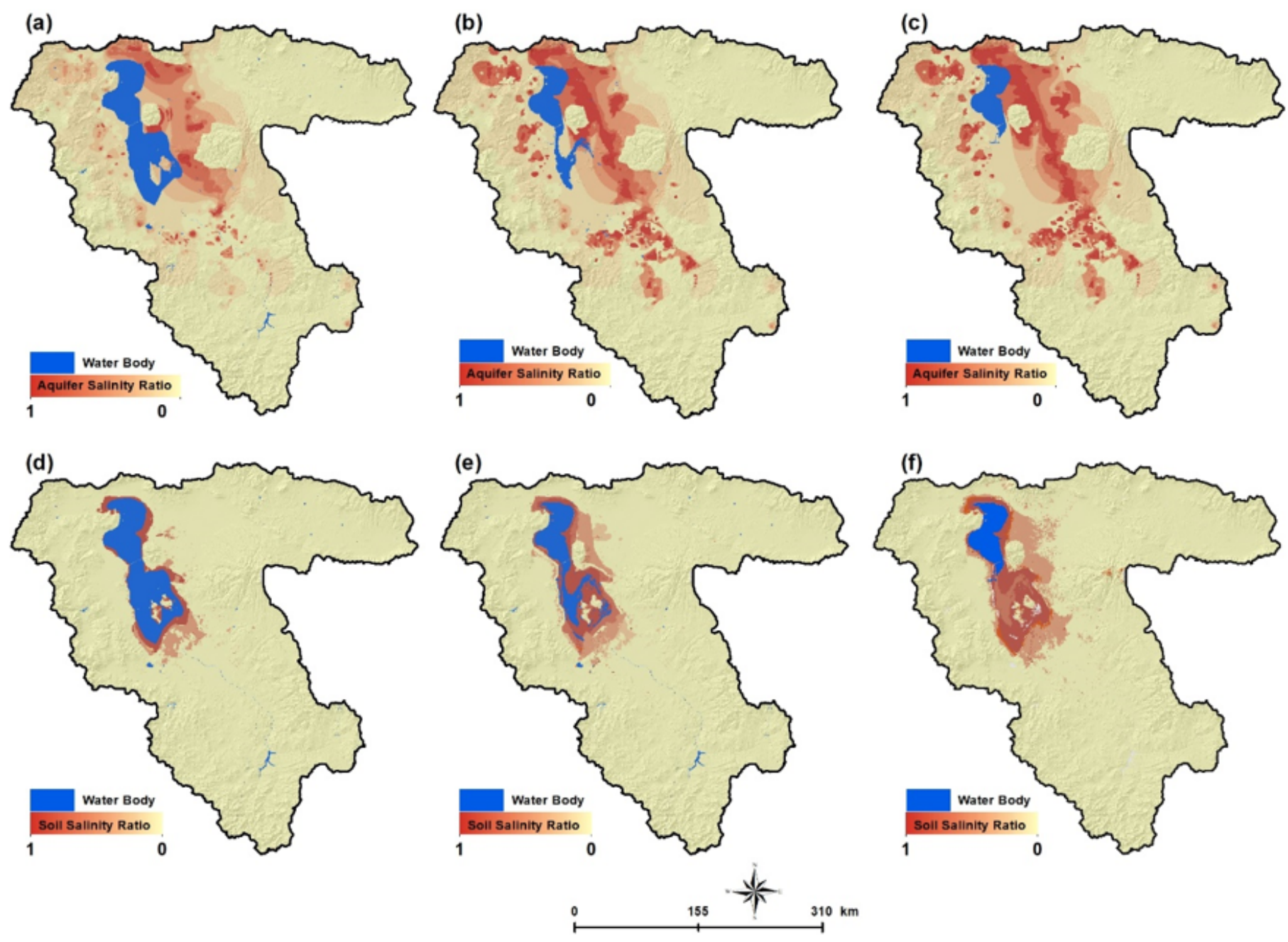

Figure 5

Results of simulation using a CA- Markov: aquifer salinization for 2030 (a), 2040(b), 2050 (c) and soil salinization for 2030 (d), 2040 (e) and 2050 (f) 


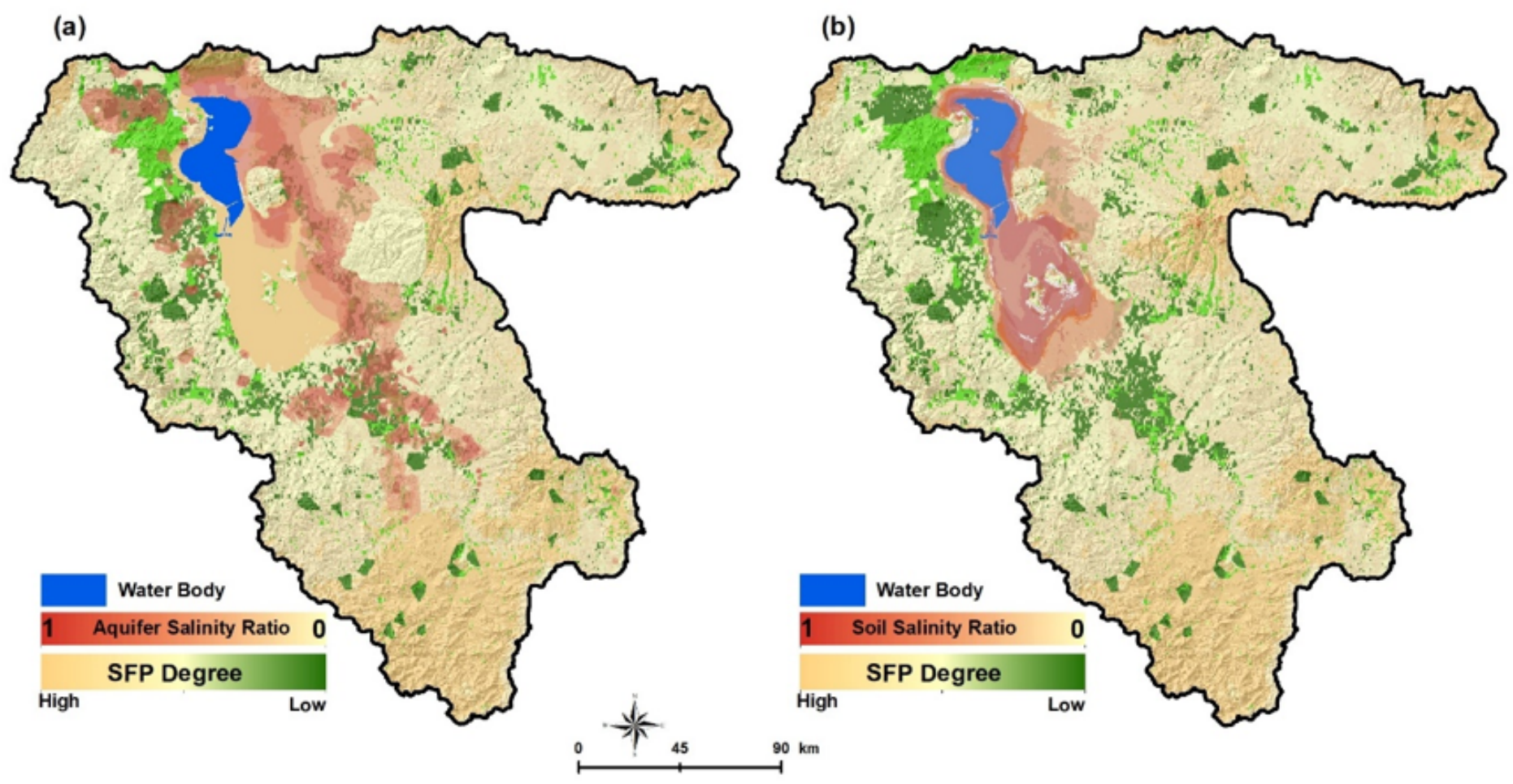

Figure 6

Results of the scenario-based FSP in spatial correlation with aquifer salinization (a) and soil salinity (b)

\section{Supplementary Files}

This is a list of supplementary files associated with this preprint. Click to download.

- Supplementarymaterials.pdf 